\title{
TECNOLOGIA E A FORMAÇÃO DE PROFESSORES UNIVERSITÁRIOS: DESAFIOS E PERSPECTIVAS
}

\begin{abstract}
Reviu Barros ${ }^{1}$
RESUMO: Este artigo tem por objetivo abordar questões quanto à formação de professores universitários, procurando contextualizar as tecnologias como um novo paradigma emergente na educação superior. Atualmente, a evolução causada pelas novas tecnologias da informação e comunicação (TICs) trouxe mudanças sociais significativas para a sociedade. $\mathrm{Na}$ esfera educacional não é diferente, do ensino básico ao superior passaram e passam por mudanças, por isso, a necessidade de acompanhar a evolução tecnológica para melhorar a aprendizagem, não aderindo à estagnação e ao obsoleto. Na modalidade qualitativa e no sentido de tratar dos desafios e perspectivas do docente no ensino superior frente às perspectivas inovadoras da tecnologia, o objetivo específico deste artigo é elencar alguns pressupostos no viés com a prática pedagógica do professor. Diante disso, surgiu a seguinte indagação: quais os desafios e perspectivas dos professores com o auxílio das tecnologias para melhorar a prática pedagógica e promover aprendizagem no século XXI? Sob essa égide, este trabalho irá se debruçar com o enfoque na educação, principalmente no ensino superior, para tentar achar resposta para a problemática dessa pesquisa e contribuir para melhorar a prática pedagógica e por fim, trazer aportes que possam corroborar para a pesquisa e a aprendizagem significativa dos alunos.
\end{abstract}

Palavras-chave: Prática Pedagógica. Formação. Professor Universitário. Tecnologia.

ABSTRACT: This article aims to address issues regarding the training of university professors, seeking to contextualize technologies as a new emerging paradigm in higher education. Currently, the evolution caused by new information and communication technologies (ICTs) has brought significant social changes to society. In the educational sphere it is no different, from basic to higher education have gone through and are undergoing changes, hence the need to keep up with technological evolution to improve learning, not adhering to stagnation and obsolete. In the qualitative modality and in the sense of dealing with the challenges and perspectives of professors in higher education in view of the innovative perspectives of technology, the specific objective of this article is to list some assumptions in the bias with the professor's pedagogical practice. Therefore, the following question emerged: what are

'graduado em Letras, Pedagogia, Especialista e Mestre em Educação. Universidade - UNINTER reviub@yahoo.com.br. CV: http://lattes.cnpq.br/868565119248258o https://orcid.org/oooo-ooor-8322$316 \mathrm{X}$ 
the challenges and perspectives for teachers with the help of technologies to improve pedagogical practice and promote learning in the 2ist century? Under this aegis, this work will focus on education, especially in higher education, to try to find an answer to the problem of this research and contribute to improve pedagogical practice and, finally, bring contributions that can corroborate research and meaningful student learning.

Keywords: Pedagogical Practice. Education. University Professor. Technology.

\section{INTRODUÇÃO}

Este trabalho procura abordar questões de ordem geral quanto à formação de professores universitários, procurando contextualizar a cibercultura como um novo paradigma emergente na educação superior. A tecnologia tem entrado cada vez mais no cotidiano profissional. As instituições educacionais, sejam elas universidades ou escolas básicas, almejam o uso desta tecnologia e investem nestes recursos de alguma forma para melhorar o ensino.

Diante desta constatação faz com que hoje o professor precise estar preparado para realizar seu trabalho consciente de que vivemos num mundo onde diversos meios podem levar ao raciocínio e ao conhecimento e de que a aprendizagem pode acontecer de várias maneiras e em diversos espaços, além da tradicional aula expositiva. $\mathrm{O}$ uso crescente dos meios audiovisuais e da tecnologia em geral na sociedade diversificou as estratégias de aprendizagem informal. Além disso, há um grande volume de informação que circula com muita rapidez e através de múltiplos meios de comunicação.

Nesse pressuposto, surgiu a seguinte indagação: quais os desafios e perspectivas dos professores com o auxílio das tecnologias para melhorar a prática pedagógica e promover aprendizagem no século XXI? Pensando haver resposta para a questão, buscou-se o apoio em diversos autores que abordam o tema, a fim de contribuir com os professores para uma possível ruptura de práticas tradicionais, uma vez que, atualmente temos um novo aluno que requer um novo professor que deve repensar suas práticas.

Sabemos que, é importante para a sociedade atual, com o crescente avanço tecnológico que o professor universitário esteja inserido em um novo conceito de 
formação repensando nas práticas de ensino e aprendizagem. "É pensando criticamente a prática de hoje ou de ontem é que se pode melhorar a próxima prática” (FREIRE,1996, p.43).

Para Castanho (200o), o sistema educativo não pode ser mudado tão fácil, conforme revelam os estudos, as inovações têm sido incapazes de transformar as escolas.

Não é fácil mudar nossas escolas. O sistema educativo tem grande capacidade de continuidade e de estabilidade. As inovações têm sido incapazes de transformar as escolas, como revelam inúmeros estudos. Toda vez que se tenta implantar um contexto de inovação e de mudança, observa-se que os mecanismos reacionários e resistentes atuam no sentido e manter tal qual o funcionamento da escola (CASTANHO, 200o, p.77).

Embora não seja tão fácil mudar o sistema educativo, o processo de inovação educacional envolve o planejamento e o desenvolvimento de iniciativas educacionais pioneiras, combinando atividades de ensino presenciais, semipresenciais e a distância, suportadas por ferramentas tecnológicas avançadas, alinhando competências, métodos e ferramentas tecnológicas para orientar tanto o professor quanto o aluno.

\section{METODOLOGIA}

Para a tessitura deste artigo, que o classificamos como uma pesquisa bibliográfica, que, segundo Gil (2017), é um tipo de pesquisa que se fundamenta com base em material já publicado em livros, artigos científicos, teses e dissertações, dentre outros.

O objetivo é abordar questões de ordem geral quanto à formação de professores universitários, procurando contextualizar a cibercultura como um novo paradigma emergente na educação superior, levando em conta a evolução tecnológica numa necessidade de professores, principalmente no ensino superior, estejam atentos às mudanças e a evolução tecnológica no meio acadêmico.

Por meio desse trabalho investigativo, colocamo-nos na posição de professor pesquisador, como declara Silva (2014, p. 67), “[...] que, estando totalmente envolvido em sua prática - e justamente por estar envolvido - levanta constantes questionamentos acerca de suas ações, a fim de encontrar caminhos para o melhor 
desempenho de suas atividades e de seus pares, e assim, contribuir para a melhoria da educação”.

É importante salientar que, um trabalho de pesquisa quando é realizado pelo próprio professor, promove a ação em reflexão para repensar a própria prática pedagógica.

Para enfatizar essa percepção, Bortoni-Ricardo (2008), confirma que:

O docente que consegue associar o trabalho de pesquisa a seu fazer pedagógico, tornando-se um professor pesquisador de sua própria prática ou das práticas pedagógicas com as quais convive, estará no caminho de aperfeiçoar-se profissionalmente, desenvolvendo uma melhor compreensão de suas ações como mediador de conhecimentos e de seu processo interacional com os educandos. (BORTONI-RICARDO, 2008, p I9).

Para a elaboração deste trabalho, foi realizado um levantamento de dados coletados, das concepções a partir de autores pertinentes ao tema em estudo, tais como: André (200I); Bortoni-Ricardo (2008); Castanho (2000); Garcia (1997); Freire (1996); Gil (2017); Masetto (1998); Masetto (2005); Mores (1996); Nóvoa (2002); Pérez Gómez (200I); Pimente (2005); Silva (2014); Tardif (2014), dentre outros.

\section{QUEM É O PROFESSOR UNIVERSITÁRIO?}

De acordo com Masetto (1998), os cursos superiores procuram formar seus profissionais por um processo de ensino no qual conhecimentos e experiências profissionais são transmitidas de um professor que sabe e conhece para o aluno que não sabe conhece, seguido por uma avaliação que diz se o aluno está apto ou não para exercer a profissão. "Em caso positivo, é-lhe outorgado o diploma ou certificado de competência que permite o exercício profissional. Em caso negativo, repete o curso. (p. Io)”.

E, quem é esse professor universitário?

Só recentemente os professores universitários começaram a se conscientizar de que a docência, como a pesquisa e o exercício de qualquer profissão, exige capacitação própria e específica. O exercício docente no ensino superior exige competências específicas, que não se restringem a ter um diploma de bacharel ou mesmo de mestre ou doutor, ou, ainda, apenas o exercício de uma profissão. Exige isso tudo, além de outras competências próprias (MASETTO, 1998, p. II). 
Segundo o autor acima citado, até a década de setenta, os professores eram pessoas formadas pelas universidades europeias; mas logo depois, com o crescimento e a expansão dos cursos superiores, o corpo docente precisou ser ampliado com profissionais de diferentes áreas de conhecimento. Ou seja, os cursos superiores ou faculdades procuravam profissionais renomados, com sucesso em suas atividades profissionais, e os convidavam a ensinarem seus alunos a serem bons profissionais, (MASETTO, 2003).

Nesse aspecto, Pimenta (2005), afirma que a maior parte das universidades, mesmo que seus professores possuam experiência significativa, e mesmo anos de estudos em suas áreas específicas, predomina o despreparo e até um desconhecimento científico do que seja o processo de ensino e de aprendizagem, pelo qual passam a ser responsáveis a partir do instante em que ingressam na sala de aula.

\footnotetext{
Examinando o panorama internacional, constata-se, nos meios educativos dos países mais avançados, um crescimento da preocupação com a formação e o desenvolvimento profissional de professores universitários e com as inovações no campo da Didática (PIMENTA, 2005, p.38).
}

A Lei de Diretrizes e Base da Educação Nacional, (LDBEN), número 9.394/96, define as diretrizes e bases da educação nacional, e o Decreto2.207/97, que regulamenta o Sistema Federal de Ensino, estimulam essa demanda, ao conterem referência explícita à preparação pedagógica para o exercício da docência superior e ao exigirem que as instituições de ensino superior contenham parcelas de seus professores titulados em nível de pós-graduação.

Segundo Pimenta (2005), o ato de ensinar no ensino superior, configura-se como um processo contínuo de construção da identidade docente e tem por base os saberes da experiência, construídos no exercício profissional mediante o ensino dos saberes específicos das áreas de conhecimento.

Neste caso, o papel do professor como apenas repassador de informações atualizadas está no seu limite, conforme ressalta Masetto (2003), uma vez que diariamente estamos sujeitos a ser surpreendidos com informações novas de que dispõem nossos alunos, as quais nem sempre temos oportunidade de ver nos números 
sites existentes na Internet. É um novo mundo, uma nova atitude, uma nova perspectiva na relação entre o professor e o aluno que se estabelece no ensino superior.

Este mesmo autor acima mencionado, aborda as mudanças no ensino superior em quatro pontos importantes: no incentivo à pesquisa, no processo de ensino, na parceria e coparticipação entre professor e aluno no processo de aprendizagem e no perfil docente.

Para Masetto (2003), o incentivo à pesquisa, iniciou-se por volta de 1930, com duas grandes metas em busca de modificar o paradigma dos cursos superiores existentes: a integração das diferentes áreas do saber e dos conhecimentos, e a produção de pesquisas por parte dos docentes e alunos desses cursos.

O motivo da Lei número 5.540, no ano de 1968, foi o incentivo à criação e ao desenvolvimento de programas de pós-graduação no país proporcionou um marco no desenvolvimento das atividades de pesquisa no ensino superior. Muitos trabalhos de pesquisas existentes se transformaram em dissertações e teses, consolidando assim o incentivo à pesquisa em todo o ensino superior." Existe um consenso na literatura educacional de que a pesquisa é um elemento essencial na formação profissional do professor" (ANDRÉ, 2001, p.55).

Segundo André (200I), a parceria e coparticipação entre o professor e aluno no processo de aprendizagem são para desencadear uma compreensão mais abrangente neste processo e sua valorização no ensino superior, através da ênfase dada ao aprendiz como sujeito do processo. A docência existe para que o aluno aprenda" (ANDRÉ, 200I, p.23).

No processo de ensino, essa é uma mudança voltada para uma preocupação exclusiva na transmissão de informações e experiências, começando por um processo de busca do desenvolvimento da aprendizagem dos alunos, de aperfeiçoar sua capacidade de pensar, de dar significado para aquilo que era estudado, de perceber a relação entre o professor e sua atividade profissional, de desenvolver a capacidade de 
construir seu próprio conhecimento, a partir de coleta de informações até a produção de um texto que mostre esse conhecimento.

Olhando por esse prisma, os quatro pontos importantes de mudanças acima mencionadas, fizeram com que o perfil do professor se alterasse de especialista, e mero transmissor de informações, para mediador de aprendizagem, que incentiva e motiva o aluno. A mudança está na transformação do cenário do ensino, em que o professor e aprendiz ocupam o centro da atividade e se tornam parceiros e coparceiros do processo similar.

Masetto (2003), apresenta o processo de incorporação de tais mudanças que incentiva o docente:

A explorar com seus alunos novos ambientes de aprendizagem, tanto
ambientes profissionais como virtuais (através da Internet) a dominar o
uso das tecnologias de informação e comunicação, a valorizar o processo
coletivo de aprendizagem (o aluno aprender não apenas com o professor e
por intermédio dele, mas com os colegas, com outros professores e
especialistas, com profissionais não acadêmicos) e a repensar e
reorganizar o processo de avaliação, agora voltada para a aprendizagem,
como elemento motivador, com feedback contínuo oferecendo informações
para que o aluno supere suas dificuldades e aprenda ainda durante o tempo
em que frequenta a matéria (p. 24-25).

Seguindo esse raciocínio, é necessário entender que a aprendizagem não é um processo estático; deve estar em consonância com as mudanças sociais. Sendo assim, Tardif (2014, p. 33) enfatiza que os professores "ocupam uma posição estratégica no interior das relações complexas que unem as sociedades contemporâneas aos saberes que elas produzem e mobilizam com diversos fins".

\section{O PERFIL DO PROFESSOR UNIVERSITÁRIO NO BRASIL}

O Instituto Nacional de Estudos e Pesquisas Educacionais Anísio Teixeira $(\mathrm{INEP})^{2}$, realizou um censo no ensino superior no ano de 2011 , para saber número total de professores que atuavam no ensino superior no Brasil. A pesquisa mostrou que o número exato de professores atuantes no ensino superior no Brasil, perfazia um total

\footnotetext{
${ }^{2}$ www.gov.br/inep/pt-br Acesso em 19 de nov. 2021.
} 
de 325.804 naquele ano. Levando em conta a possibilidade de o professor universitário possuir mais de um vínculo profissional, o censo trouxe 378.257 atuantes nessa modalidade. Dentre esses, 357.418 estavam na ativa, sendo que, 60\% desses professores atuavam em Instituições de Ensino Superior (IES) particulares. Quanto à formação dos professores, o percentual foi de: $16,5 \%$ eram doutores, 44,1\% mestres e $39,4 \%$ eram especialistas.

Uma peculiaridade que mostrou o censo de 20 Ir foi que, cerca de (8I,o\% desses professores trabalhavam em período de dedicação exclusiva nas instituições públicas. Apenas, 43,8\% atuavam em instituições particulares de modo que permitia a estes trabalhar em mais de uma instituição de ensino e ou exercer outra atividade profissional.

Ainda de acordo com o INEP, ao designar o perfil do docente no ensino superior mostrou que professor atuante em instituições particulares era homem, com idade que oscilava em média de 34 anos, possuía titulação de mestre e remunerado por hora aula. Já o professor que atuava em instituições públicas era também homem, com idade de 47 anos, geralmente possuía o título de doutor, e trabalhava em regime de dedicação exclusiva.

Os autores Gripp e Testi (20II), pontuam em seu estudo realizado sobre as concepções de Simon Schwartzman e Elizabeth Balbachevsky (1997), que especificam em três grupos as categorias dos professores universitários brasileiros. São elas:

I) Professores em tempo parcial, sem estabilidade, com baixa especialização acadêmica, com uma carga horária elevada de aulas e prestando serviços ao setor privado.

2) Professores com qualificação média, estáveis, de tempo integral, com grande envolvimento em atividades sindicais e produção científica relativamente pequena.

3) Professor mais qualificado, envolvido em pesquisa com financiamento próprio, com pouca participação sindical e grande envolvimento com associações acadêmicas no país e no exterior.

Mas, para Behrens (20II), por meio de seus estudos, mostrou que existem quatro grupos representativos de profissionais que atuam na universidade: 
I) Profissionais de variadas áreas do conhecimento e que se dedicam à docência em tempo integral;

2) Profissionais que atuam no mercado de trabalho específico e se dedicam ao magistério algumas horas por semana;

3) Profissionais docentes da área pedagógica e das licenciaturas que atuam na universidade e, paralelamente, no ensino básico (educação infantil, ensino fundamental e (ou) ensino médio);

4) Profissionais da área da educação e das licenciaturas que atuam em tempo integral nas universidades.

Nessa concepção, Morosini (200o), vai dizer que:

Encontramos exercendo a docência universitária, professores com formação didática obtida em cursos de licenciatura; outros, que trazem sua experiência profissional para a sala de aula; e, outros ainda, sem experiência profissional ou didática, oriundos de curso de especialização e/ou stricto sensu. O fator definidor da seleção de professores, até então, era a competência científica (MOROSINI, 200o, p.II).

Diante ao exposto às concepções dos autores acima citados, e, com base nos

dados obtidos nesse estudo, percebe-se que os professores do ensino superior não têm uma identidade única, suas características variam muito, principalmente em relação às instituições de ensino onde exercem à docência, e em relação a trajetória de vida e de formação profissional de cada um desses professores.

\section{UMA NOVA FORMAÇÃO DO PROFESSOR UNIVERSITÁRIO}

Há algumas décadas, acreditava-se que, quando terminada a graduação, o profissional estaria apto para atuar na sua área o resto da vida. Atualmente, tudo mudou, principalmente para o professor. Para este, deve estar consciente de que sua formação é permanente, e é integrada no seu dia a dia nas escolas.

A formação continuada se dá de maneira coletiva e depende da experiência e da reflexão como instrumentos contínuos de análises. Para Nóvoa (2002), “o aprender contínuo é essencial e se concentra em dois pilares: a própria pessoa, como agente, e a escola, como lugar de crescimento profissional permanente" (p.23). Cada vez mais imersos na cibercultura, os alunos exigirão um novo ambiente de aprendizagem. Eles 
passam a integrar a chamada "geração digital" e estão cada vez menos passivos perante a mensagem fechada à intervenção. Assim, eles migram da tela estática da TV para a tela do computador conectado à Internet.

A teoria e prática do professor poderão contribuir para melhorar a qualidade do ensino, sendo que os programas de formação de professores precisarão abordar questionamentos inadiáveis, como por exemplo: o que é cibercultura? Por que a cibercultura convoca o professor a reinventar sua sala de aula? Como situar participação, dialógica em multidisciplinaridade nesse ambiente garantindo a formação cidadã no contexto midiatizado? A sequência deste texto busca contribuir para o tratamento dessas questões.

A formação oportuniza ao docente não só o saber em sala de aula, ele precisa conhecer as questões da educação, as diversas práticas analisadas nas perspectivas histórico e sociocultural, e, ainda, precisa conhecer o desenvolvimento do seu aluno nos seus múltiplos aspectos: afetivo, cognitivo, e social, bem como refletir criticamente sobre seu papel diante de seus alunos e da sociedade. Munido desses saberes elementares, os frutos serão colhidos no ambiente de sala de aula ou fora dele.

Conforme relata Masetto (2003), os objetivos que poderão ser alcançados por meio da inserção das novas tecnologias na educação são: valorizar a autoaprendizagem, incentivar a formação permanente, desenvolver a interaprendizagem: a aprendizagem como produto das inter-relações entre pessoas, entre outros.

Desse modo, Pimenta (2005), vai afirmar que a docência na universidade, configura-se como um processo contínuo de construção da identidade docente e tem por base os saberes de experiências, construídos no exercício profissional mediante o ensino de saberes específicos. As transformações das práticas pedagógicas só se efetivam à medida que o professor amplia sua consciência sobre a própria prática, a da sala de aula, e a prática da Universidade como um todo, o que pressupõe os conhecimentos teóricos e críticos sobre a realidade.

Na concepção de Pérez Gómez (200I), não é tão fácil promover a transformação qualitativa do saber docente para práticas mais inovadoras e criativas quando se deteriora em marchas forçadas seu status e sua consideração social. E para todas as 
adversidades e perplexidades que seguem o processo de profissionalização do professor na atualidade, requer um esforço superior, ou seja, o de reconsiderar o sentido e a natureza do que pensamos construir sua atividade profissional.

Para esse mesmo autor acima citado, é importante uma exigência de renovação permanente para fazer frente às necessidades mutáveis da sociedade, ao incremento impetuoso do conhecimento científico e cultural, às características peculiares e desconhecidas de cada geração de estudantes.

Segundo Pimenta (2005):

O ensino como prática reflexiva tem se estabelecido como uma Tendência
significativa nas pesquisas em educação, apontando para a valorização de
processos de produção do saber docente a partir da prática e situando a
pesquisa como um instrumento de formação de professores, em que o ensino
é tomado como ponto de partida e de chegada da pesquisa (PIMENTA 2005,
p.22).

Para isso, uma mudança de paradigma na educação que deve ser entendida e colocada em prática pelos profissionais da Educação, não somente professores, mas pela gestão pedagógica. Com efeito, apenas com um entendimento comum entre gestão e professores é que a formação de cidadãos preparados para os desafios do século XXI pode ser concretizada.

\section{O IMPACTO DAS TECNOLOGIAS NA FORMAÇÃO DOCENTE}

É fato que, a educação de modo geral, principalmente na universidade está vivenciando o impacto da revolução tecnológica sobre a produção e socialização do conhecimento e formação de futuros profissionais da educação. Tornando-se assim, necessário, repensar na formação atualmente oferecida aos futuros professores universitários e até mesmo àqueles que já exercem suas funções. Percebe-se que a revolução tecnológica é um fato irreversível e que atinge diretamente o ambiente de ensino, não sendo possível ignorar sua presença e importância.

Por isso, o ensino superior precisa se abrir não somente ao diálogo com outras fontes de produção de conhecimento e de pesquisa, de igual modo, o professor deve assumir o papel de intermediador e colaborador na busca da informação, aquisição e elaboração do conhecimento. A crescente perspectiva de diversificar os espaços 
educacionais impõe um aprendizado sem fronteiras, mostrando a necessidade de profissionais com maiores conhecimentos e habilidades para atuarem dentro dos novos processos organizacionais com alta agregação de informática.

Os recursos tecnológicos são instrumentos para mudança e melhoria na qualidade do ensino-aprendizagem, exigindo que os professores tenham sólidos conhecimentos da didática e dos conteúdos, e que usem as novas tecnologias como ferramenta para atender as necessidades individuais e coletivas e para estimular a construção criativa e a capacidade de reflexão.

Sabe-se que a Internet é um recurso de aprendizagem autônoma, pois o aluno busca informações de forma flexível e crítica, tendo a liberdade de escolha.

Neste sentido, Moraes (1996):

Pressupõe a busca de informações onde quer que elas estejam pelo domínio de diferentes formas de acesso informação associado ao desenvolvimento de uma atitude crítica de investigação, no sentido de que o indivíduo seja capaz de avaliar, reunir e organizar as informações mais relevantes. Isso implica que o indivíduo seja capaz de comparar informações diferentes, com ideologias e valores diversos (...). $\mathrm{O}$ desenvolvimento da criticidade facilita a identificação fonte de produção da informação, a análise da sua validade e a possibilidade de compará-la, decidindo qual será mais útil para o desenvolvimento de seu trabalho (...). O aprendizado autônomo pressupõe flexibilidade, facilidade para mudar valores, para promover diálogos e habilidade de comunicação no que se refere à cooperação à coordenação e a à decisão decorrentes das vivências de trabalho em grupo na procura de soluções conjuntas para os problemas. (MORAES, 1996, p. 223/224).

No entendimento de Garcia (1997), a rede pode ser considerada a mais completa, abrangente e complexa ferramenta de aprendizagem do mundo e os benefícios da utilização das redes estão diretamente relacionados às novas formas de aprendizagem em que a interação, o acesso ilimitado às informações, a questão multidisciplinar e colaborativa se unem para redimensionar os modelos educacionais.

Sabe-se que, as tecnologias da informação e comunicação têm como aliados a rede mundial, os softwares e os computadores. A utilização da Internet como meio de comunicação possibilita a troca de programas, imagens e textos, buscando facilitar e agilizar a crescente demanda pelo saber. A progressiva utilização de cursos online funciona como alternativa para o desenvolvimento de novos ambientes de aprendizagem 
A universidade, hoje necessita de profissionais que sejam capacitados na busca de novas informações que tenham condições de trocar informações através dos recursos mais modernos da informática em todo o território nacional e internacional e que se preparem para desempenhar suas profissões de forma contextualizada e em equipe com profissionais não só de sua área, mas também de outras.

A busca contínua de novos conhecimentos é um dos fatores do desenvolvimento econômico e um dos polos da educação. $O$ professor universitário terá que buscar alternativas de busca de conhecimento de forma a se manter capaz de desenvolver novas competências para estar em condição de atender às contínuas exigências e aos desafios impostos pelo mercado de trabalho, e consequentemente pelo impacto da utilização de novas tecnologias no ensino superior.

De acordo com Moran (2006), o processo de ensinar em paralelo com o processo de aprender atualmente obriga que o educador tenha uma maior flexibilidade, interpessoal e em grupo, ser menos conteudista e possuir uma maior abertura em seus processos de interconexões. $\mathrm{O}$ autor ainda reitera que com os avanços tecnológicos o trabalho docente não pode ser mais desenvolvido usando um único espaço - a sala de aula - e sim criar um processo não linear de ensino aprendizagem, desenvolvendo melhor sua criatividade nas práticas pedagógicas.

Para Masetto (2006), essa é uma nova maneira de ensinar, fácil para os educadores tradicionalistas, pois cada aluno tem um tempo/ritmo diferenciado para assimilar os objetivos da aprendizagem. Dessa forma para o referido autor o educador necessita variar as formas de motivação do educando, bem como para responder aos distintos ritmos e formas de aprendizagem diferentes.

Nesse aspecto, as tecnologias devem ser inseridas na educação superior com o intuito de proporcionar a sociedade acadêmica novas maneiras de produzir e transmitir o conhecimento. Ainda conforme o autor, em seu trabalho "Mediações pedagógicas e uso das tecnologias", observa-se que o uso das tecnologias deve valorizar o processo de aprendizagem, estimular a formação contínua e permanente, a pesquisa de novas informações, o diálogo, a construção das reflexões interpessoais. 
Conforme Belloni (200I), as tecnologias estão promovendo significativas mudanças no sistema educacional, essa autora enfatiza que, precauções precisam ser tomadas para nortear o uso das TICs na educação superior, com o fascínio pelas tecnologias o professor pode acabar realizando uso ineficiente e promovendo assim uma contraposição com os objetivos previstos. Por outro aspecto, a utilização das TICs na educação contribui para uma melhor relação entre ensino e o contexto externo das instituições, como também transforma as interrelações sociais.

$\mathrm{Na}$ concepção de Zabalza (2004), o educador precisa não só apenas conhecer os conteúdos ele deve também ser capaz de analisar, entender e resolver problemas, tornar tópicos compreensíveis, aproximar os conteúdos de circunstâncias atuais, ter estratégias metodológicas e selecionar recursos tecnológicos ou não para que possa facilitar o processo de aprendizagem, identificar o que o aluno sabe, interrelação com os alunos e saber agir de acordo as condições impostas pelo grupo com quem se trabalha.

Esse autor ainda ressalta que:

O objetivo da docência é melhorar os resultados da aprendizagem dos alunos e aperfeiçoar a sua formação. Isso implica, sem dúvida, grandes esforços didáticos para adequar a organização dos cursos e métodos de ensino utilizados aos diferentes modos e estilos de aprendizagem dos alunos e aos seus diversos interesses profissionais, já que se trata de adultos. As estratégias às quais os estudantes recorrem para aprender, os problemas que vão enfrentar nesse processo, a forma como é afetada a aprendizagem pela incorporação das novas tecnologias ou pelas novas situações de aprendizagem (Ensino à distância, por exemplo), constituem elementos que permanecem ainda em uma zona relativamente desconhecida do conhecimento profissional. Porém os professores são levados a transitar em um contexto cada vez mais heterogêneo de estudantes, os quais têm diversos interesses, diversas motivações, capacidades e expectativas (ZABALZA, 2004, p.189).

Nesse sentido, é necessário que as universidades proporcionem para sua sociedade acadêmica facilidades de acesso e utilização de hardware, software e outras tecnologias com base para o desenvolvimento profissional e pessoal deles. Seguindo esse pensamento a UNESCO (2002), propõem um rol de condições para a adoção das tecnologias da informação e comunicação em organizações educacionais. Observa-se na tabela a seguir. 
Tabela I. Condições para implantar a adoção das TICs em uma organização educacional.

Visão Compartilhada

Acesso

Docentes Capacitados

Desenvolvimento pessoal

Assistência Técnica

Recursos didáticos e relação com conteúdo programático

Aluno como sujeito integrado num processo dialógico

Avaliação

Relação com a comunidade

Políticas de suporte
Há uma liderança proativa e suporte administrativo que permeia toda a organização.

Professores e funcionários técnico administrativos têm acesso a hardwares, softwares e redes de telecomunicações

Professores habilitados para o uso de tecnologia em processo de ensino aprendizagem.

Professores e técnico administrativos contam com programas de desenvolvimento profissional para apoiar a adoção de tecnologia em controles acadêmicos e na relação de ensino aprendizagem.

Há disponibilidade de assistência para manutenção e uso das tecnologias.

Docentes têm conhecimento suficiente na sua área de atuação quanto às diretrizes curriculares e metodológicas adequadas ao seu campo de conhecimento.

O contexto e o aluno são considerados na elaboração de projetos didáticopedagógicos que adotam as TICs. A participação crítica do estudante e valorizada.

A avaliação permanente é realizada para checar a efetividade do uso da tecnologia especialmente na relação de ensino aprendizagem

A organização educacional é aberta à comunidade para utilização de recursos, prestação de serviços e apoio na adoção das TICs, numa relação de reciprocidade.

As políticas, tais como plano de carreira e sistemas de reconhecimento, incluem e apoiam, de forma diferenciada, a adoção de tecnologia.

Fonte: Adaptada de Santos, A. Tecnologias de informação e comunicação: limites e possibilidades no ensino superior. Revista Brasileira de Ensino Superior, v. I, n. I, p. 36-46, 2015.

Desse modo, Kenski (2003), fala que as modernas tecnologias da informação e comunicação impõem uma reestruturação complexa no sistema educacional superior e não só nos procedimentos, objetivos e metodologias de ensino, as instituições de ensino superior precisam realizar mudanças organizacionais, gerenciais e avaliativas da educação e não apenas mudar as disciplinas ou os métodos pedagógicos para a efetiva utilização das redes de ensino. 
Para esta autora, tudo que é usado no cotidiano de nossas vidas, seja ela, pessoal, profissional são formas diferenciadas de tecnologias, com isso é importante expor as influências das TICs nas nossas vidas e na sociedade.

Sobre as tecnologias em nossa vida, a autora diz:

[...] ela está em todo o lugar, já faz parte de nossas vidas. Nossas atividades cotidianas mais comuns como dormir, comer, trabalhar, ler, conversar, deslocarmo-nos para diferentes lugares são possíveis graças às tecnologias que temos acesso. As tecnologias estão tão próximas e presentes, que nem percebemos mais que não são coisas naturais. Tecnologias que resultaram, por exemplo, em talheres, pratos, panelas, fogões, geladeiras, alimentos industrializados e muitos outros produtos, equipamentos e processos que foram planejados e construídos para podermos realizar a simples e fundamental tarefa que garante nossa sobrevivência: a alimentação (KENSKI, 2003, p.95).

Partindo desse pressuposto, o uso das tecnologias da informação e comunicação na educação superior, a partir do contexto de suas ferramentas como imagens, textos, áudios, vídeos e ambientes virtuais, devem possibilitar aos membros da sociedade acadêmica uma interação via internet afim de propiciar a formalização de trabalhos, avaliações e discussões para uma formação condizente com a realidade atual.

Kenski (2003), vai confirmar essas proposições dizendo que:

Devemos enfatizar que as TICs devem ser vistas como instrumentos de mediação no processo ensino aprendizagem e não como uma ferramenta principal da construção do conhecimento. A utilização das novas tecnologias afeta todos os campos educacionais. Elas encaminham as instituições para a adoção de uma "cultura informática educacional" que exige uma reestruturação sensível não apenas das teorias educacionais, mas da própria percepção e ação educativa (KENSKI, 2003, p.86).

Por isso, as instituições educacionais de ensino superior, precisam cada vez mais criar orientações em seu projeto político pedagógico no tocante a utilização das tecnologias da informação e comunicação (TICs), no processo que envolve a pesquisa, o ensino, a formação docente, atribuições administrativas, financiamento e administração das TICs e por fim uma reorientação organizacional oferecendo uma melhor qualidade de ensino, principalmente no ensino superior.

A evolução tecnológica que acontece no meio educacional, e que está trazendo mudanças tanto no ambiente físico de aprendizagem quanto virtual, vai ser reafirmada por Moran (2002), quando pontua que: 
[...] está acontecendo uma mudança reorganizando o espaço físico dos prédios das escolas, onde se verão menos salas de aulas, porém mais funcionais, com acesso à internet. Alunos estarão equipados com laptops pessoais para pesquisa, acesso a materiais e solução de alguns problemas. Para isso o professor também estará mais conectado, seja em casa ou na sala de aula com todos os recursos tecnológicos disponíveis para exibição e apoio de suas aulas, tornando assim ambientes mais participativos. As bibliotecas viram espaços de integração de mídias, software e banco de dados. O que acontecerá será uma maior integração entre a tecnologia e as metodologias de ensino oral, escrita e audiovisual (MORAN, 2002, p.102).

Portanto, o uso das tecnologias da informação e comunicação na educação superior é importante ao ponto que as instituições de ensino, professores, alunos e todo o meio acadêmico devem estar cientes que essas mudanças e adaptações das TICs na educação superior de maneira que seja feita com positividade e efetividade para o processo de ensino aprendizagem proporcionando o despertar por novos conhecimentos. Nesse aspecto, o grande impacto que o uso das TICs pode trazer para a educação superior não está na relação das estruturas tecnológicas, mas sim, no desenvolver das condições culturais sociais e econômicas de uma sociedade.

Enfim, o trabalho pedagógico do professor está continuamente exigindo destes profissionais o desempenho de novas habilidades e competências, como consequência das mudanças organizacionais, curriculares, extracurriculares e políticas da educação (ROSA, 2013). Para Perrenoud (2002), a transformação do indivíduo em um profissional reflexivo não pode sofrer improvisação. Aplicar meramente a cultura teórica não constrói hábitos nem as competências para as práticas da reflexão e não se demonstra suficiente, porém por muitas vezes se faz necessária. Primordialmente é preciso a participação dos professores em pesquisas. Portanto, esse deve ser um objetivo que pode estar presente nos currículos de formação dos profissionais de educação, principalmente no ensino superior.

\section{CONSIDERAÇÕES FINAIS}

As necessidades do século XXI já não permitem mais gestões escolares que não reflitam, que não dialogam com os professores e com os discentes. O século XXI exige o diálogo e a colaboração forte entre gestão, professores e alunos, enfatizando que 
somente pela parceria e pelo diálogo a escola poderá alcançar o seu patamar de excelência.

Por sua vez, os alunos afirmam que a escola ainda não os entende como nativos digitais; eles pedem para serem escutados pelos professores, que desejam aprender, mas aprender de forma prazerosa e que essa aprendizagem seja significativa. Assim, considera-se que o processo de aprendizagem é uma parceria entre tecnologias, gestão, professor e aluno, nessa ordem, pois as tecnologias se modificam todos os dias com o surgimento de novos softwares, aparelhos, aplicativos etc., e a gestão deve estar atenta às mudanças, passando aos professores as orientações necessárias, e estes neste caso, os do ensino superior que devem se permitir aprender para que possam realizar um trabalho profícuo com os seus alunos para uma aprendizagem significativa.

A verdade é que estamos caminhando para uma formação de professores que traz referência nos saberes que já possuem e, neste caso, novas concepções podem surgir daquilo que está intrínseco nesses sujeitos, uma vez que podem reconstruir novos conhecimentos por meio da interação entre os sujeitos. Destarte, os professores produzem saberes docentes e conhecimentos em suas práticas pedagógicas a partir do que já vivenciaram no cotidiano de trabalho escolar. Nesse pressuposto, pondera-se que a experiência se torne um saber, para isso a caracterizamos exclusiva, e que os sujeitos não terão a oportunidade para vivenciar da mesma maneira, uma experiência mais de uma vez, pois a cada vez que passar por ela será permutado por um modo desigual. E, assim, como postulado anteriormente neste trabalho, os professores não denegaram os conhecimentos que são produzidos pela experiência, ao contrário, eles os aprovam e os introduzem em suas práticas pedagógicas atuais nas instituições de ensino do básico ao superior.

Portanto, para uma formação do professor atender as exigências do novo processo educacional, é necessário conceber que a educação continuada é condição fundamental para a profissão docente. Sem descartar que, uma atuação de qualidade do professor brasileiro em um mundo informatizado vai depender da melhoria significativa de sua formação, de forma a atender às demandas atualmente na sociedade. 
Espera-se que os pressupostos aclarados neste artigo, venham contribuir para um repensar para formação em um novo docente no ensino superior, e que, esses pareceres não sejam meramente diagnósticos, passivo e casual. Mas, que ajudem a procurar, desvendar novas maneiras de formar/trabalhar, com o uso das tecnologias, e assim, melhor auxiliar o professor na função de mediador, dentro de novos olhares nos paradigmas da educação na atualidade no ensino superior.

Nesse sentido, procurar-se-á contribuir para direcionar capacitações eficientes para a formação de professores e o uso das tecnologias, e para isto, é necessário que esses profissionais e o projeto político-pedagógico possam repensar nestes pressupostos, tão necessários na possível ruptura de modelos anteriormente aplicados. De modo que, esses docentes possam rever suas concepções atentando evoluir na formação e no paradigma das práticas pedagógicas, para se obter um melhor processo de ensino/aprendizagem dos alunos, na intenção e o vínculo epistemológico do “modus operandi" de ser ou fazer educação, principalmente no ensino superior.

\section{REFERÊNCIAS BIBLIOGRÁFICAS}

ANDRÉ, Marli. O papel mediador da pesquisa no ensino da didática. In: ANDRÉ, M. e OLIVEIRA, M. R. (orgs.) Alternativas do ensino da didática. Campinas, SP, Papirus, I997.

BEHRENS, Marilda Aparecida. Docência universitária: formação ou improvisação? Revista Educação, Santa Maria, v. 36, n. 3, p. 441-454, set./dez. 2oIr.da Pesquisa na Formação e na Prática dos Professores. Campinas, Papirus, 2001.

BELLONI, M.L. Mediatização: os desafios das novas tecnologias de informação e comunicação (NTIC). In: BELLONI, M.L. Educação à distância. (2. ed., cap, 4, pp 53 - 77). Campinas: Autores Associados, 2001.

BORTONI-RICARDO, S. M. O professor pesquisador: introdução à pesquisa qualitativa. São Paulo: Parábola Editorial, 2008. 
CASTANHO, Sérgio e CASTANHO, Maria Eugênia L.M. (Org.). Pedagogia

Universitária: A aula em foco. 3 ed. Campinas, Papirus, 2000.

FREIRE, Paulo. Pedagogia da Autonomia. 2o. ed. São Paulo: Paz e Terra, 1996.

GARCIA, P. S. Redes Eletrônicas no ensino de Ciências:Avaliação Pedagógica do Projeto Ecologia em São Caetano do Sul. (Dissertação de Mestrado em Engenharia de Produção). Universidade Mackenzi, 1997.

GIL, A. C. Como elaborar projetos de pesquisa. 5 ed. São Paulo: Atlas, 2017.

GRIPP, Glícia S e TEST, Bruno Moret. Trajetórias acadêmicas: um estudo comparado da carreira acadêmica em Minas Gerais. Revista Sociedade e Estado - Volume 27 Número I - Janeiro/abril 2012.

KENSKI, V. M. Tecnologias e ensino presencial e a distância. $3^{\circ}$ ed. Campinas, SP. Papirus, 2003.

MASETTO, Marcos Tarciso. Professor Universitário: Um Profissional da Educação na Atividade Docente. In: MASETTO, Marcos Tarciso (Org.). Docência na Universidade. 7 ed. Campinas: Papirus, 1998.

MASETTO, Marcos Tarciso. Competência Pedagógica do Professor Universitário. São Paulo: Summus, 2003.

MASETTO, M. T.; BEHRENS, M.A. Novas tecnologias e mediação pedagógica. Campinas, SP: Papirus, 2006. 
MORAES, Maria Cândida. O Paradigma Educacional Emergente. Campinas, SP. Papirus 1997.

MORAN, J.M. Ensino e aprendizagem inovadores com tecnologias audiovisuais e telemáticas. In: MORAN, J.M.; MASETTO, M. T.; BEHRENS, M.A. Novas tecnologias e mediação pedagógica. Campinas, SP: Papirus, 2006.

MOROSIN, Marília. Docência universitária e os desafios da realidade nacional. Instituto Nacional de Estudos e Pesquisas Educacionais, Brasília: Instituto Nacional de Estudos e Pesquisas Educacionais, n.2, p.II-2I, 2000.

NÓVOA, Antonio. (Coord.). Os Professores e Sua Formação. Lisboa-Portugal: Dom Quixote, 1997.

PÉREZ GÓMEZ, A. I. A Cultura Escolar na Sociedade Neoliberal. São Paulo:Artmed Editora, 20or.

PERRENOUD, P. A prática reflexiva no ofício de professor: profissionalização e razão pedagógica. Porto Alegre: Artmed, 2002.

PIMENTA, Selma Garrido. Professor Reflexivo: Construindo uma Crítica. In: PIMENTA, Selma Garrido e GHEDIN, Evandro. (Org.). Professor Reflexivo no Brasil: Gênese e Crítica de um Conceito. 3. ed. São Paulo: Cotez, 2005.

ROSA, R. Trabalho docente: dificuldades apontadas pelos professores no uso das tecnologias. Revista Encontro de Pesquisa em Educação. Uberaba, v.I, n.I, p. 214 - 227, 2013.

SILVA, A. J. N. A Ludicidade no Laboratório: considerações sobre a formação do futuro professor de matemática. Curitiba, PR: Editora CRV, 2014. 
TARDIF, Maurice. Saberes docentes e formação profissional. i6 ed. Petrópolis, RJ: Vozes, 2014.

UNESCO. Information and communication technology in education: a curriculum for schools and programme of teacher development. Paris, 2002. Disponível em: http://unesdoc.unesco.org/images/oor2/oor295/129538e.pdf Acesso em io fev.2020.

ZABALZA, M. A. O ensino universitário: seu cenário e seus protagonistas. $\mathrm{I}^{\mathrm{a}}$ Edição. Porto Alegre. Artmed, 2004. 